\title{
A TRADUÇÃO TARDIA DO QUIXOTE EM PORTUGAL
}

\section{Silvia Cobelo ${ }^{1}$}

RESUMO: O presente trabalho é uma digressão sobre um fato histórico: a inexistência de uma tradução do Quixote em Portugal por 189 anos, período em que a obra foi editada e lida em espanhol. Inicia-se com um panorama da recepção da obra nesse país desde 1605 até 1793. Em 1794 aparece a primeira tradução ao português, sem indicação de tradutor, editada três vezes. Somente em 1876 surge a primeira tradução assinada, pelos Viscondes de Castilho, de Azevedo e por Pinheiro Chagas. Nesse ensejo, são discutidas as condições históricas e linguísticas que possibilitariam o fato da inexistência da tradução por quase dois séculos, com foco no bilinguismo cultural luso-espanhol que durou 250 anos. Ao final, apresenta-se um trecho do início da obra retirado das edições mencionadas. Por meio dela é possivel que se visualize a maneira como O Quixote era lido pelos leitores dos séculos XVII, XVIII e XIX. A partir de então, apresentamos um diálogo entre alguns estudos da tradução, relacionando alguns temas como proximidade linguística, bilinguismo linguístico e cultural e seus reflexos nas traduções.

PALAVRAS-CHAVE: Quixote; Historiografia da tradução; Bilinguismo; Portugal; Tradução espanhol-português.

1 Doutoranda do Programa de Pós-Graduação em Língua Espanhola e Literaturas Espanhola e Hispano-americana, DLM - FFLCH/USP.

TRadTerm, 16, 2010, p. 193-216 
ABSTRACT: This paper is a digression on a historical fact: the lack of a translation of Quixote in Portugal for 189 years, during which the work was edited and read in Spanish. It begins with an overview of the novel's reception in this country from 1605 to 1793. The first translation into Portuguese is from 1794, with no indication of a translator, published three times. Only in 1876 is published the first translation, signed by the Viscount de Castilho, de Azevedo and Pinheiro Chagas. Then, the historical and linguistic conditions that would allow the fact of the absence of translation for almost two centuries, focusing on cultural Luso-Spanish bilingualism which lasted 250 years. In the end, it is offered an example; an excerpt from the Quixote's beginning, removed from the cited publications, so that readers can view the Quixote as it was read by the readers of the XVII, XVIII and XIX centuries. It concludes with a dialogue between some translation studies related to the theme, to support the proposal of this article.

Keywords: Quixote; Translation historiography; Bilingualism; Portugal; Spanish-Portuguese translation.

\section{O Quixote lido em espanhol}

Em 1605, nos primeiros dias de janeiro, surge em Madri o livro El Ingenioso Hidalgo Don Qvixote de la Mancha, escrito por Miguel de Cervantes Saavedra. O êxito da obra fez com que fosse impressa por três vezes no mesmo ano em Portugal: a primeira de Jorge Rodriguez, com licença de 27 de fevereiro de 1605, seguida da de Pero Crasbeeck, com licença de 27 de março e a terceira sendo desconhecida até o século XX, igualmente de Jorge Rodriguez, considerada uma nova "tiragem", também data de 1605. A hispanista portuguesa Maria Fernanda de Abreu (2006:299) acredita que as edições feitas em Lisboa seriam uma das maiores provas do sucesso da obra, e a existência de dois impressores com datas de licenças tão próximas revelaria uma disputa para imprimir o livro em Portugal.

TradTerm, 16, 2010, p. 193-216 
Essas edições são até mesmo mencionadas no Quixote de 1615. No capítulo três, a personagem Sansão Carrasco conta a Dom Quixote que mais de 12 mil livros já haviam sido impressos, inclusive em Portugal, Barcelona, Valencia e Amberes. Diz também que a obra estava sendo traduzida em outros paises (Cervantes, 2004:567). E Sansão Carrasco não estava enganado, pois, de fato já existiam duas traduções completas da obra: uma em 1612 na Inglaterra, outra em 1614 na França. A obra teria sido bastante lida em Portugal durante o período em que esteve disponivel somente no idioma original; Tomé Pinheiro da Veiga, cronista da corte do rei Filipe III, relatou as festas da celebração do nascimento de Filipe IV em Valladolid em junho de 1605, referindo-se a um Dom Quixote e Sancho Pança. Essa crônica seria inclusive o "primeiro documento da recepção produtiva do Dom Quixote com que, cronologicamente, conta hoje o cervantismo mundial" (Abreu, 2006:299). Abreu (1994:70) cita Francisco Rodríguez Marin ${ }^{2}$ para quem Pinheiro da Veiga teria lido a obra de Cervantes, seguindo ela mesma tal interpretação.

Em 1642, dois anos após a Restauração da Coroa Portuguesa, é impressa em Lisboa uma peça paródica ilustrada com dois cavaleiros duelando, o que lembra a capa da terceira edição portuguesa do Quixote (Jorge Rodriguez, 1605). São seis páginas, escritas num "castellano pasado y paseado por la Rua Nova de Lisboa" (Marin apud Abreu, 1994:70). Nesse documento, os portugueses recorriam à figura de Dom Quixote para expressar o orgulho da liberdade conquistada.

Em 1733 Antonio José da Silva, "O Judeu", escreve uma peça de teatro: A Vida do Grande D. Quixote de la Macha e do Gordo Sancho Pança. Abreu (1994) aponta o trabalho de José Ares Montes (1953), em que além da peça do "Judeu", o pesquisador apresenta três entremeses relacionados com episódios ou personagens do Quixote. Destaca um entremes de 1774, O Grande Governador da Ilha dos Lagartos, uma paródia do episódio de Sancho como governador de Barataria.

Outro lugar onde a pesquisadora portuguesa encontra ecos da leitura do Quixote é na literatura de cordel. Neste exemplo de

2 MARIN, F. R. (1947). Estudos Cervantinos. Madrid: Ediciones Atlas. 
autoria anônima, notar que o autor desconhecido se refere ao episódio do Clavileño, narrado entre os capítulos XL e XLIII do segundo livro, mostrando que a obra era lida integralmente, algo que não acontece muito hoje em dia $^{3}$ :

(...) leia a História de D.Quixote, que quis desafiar ao Gigante Malambruno, para o que montou naquele cavalo de pau, chamado clavilenho, que andava mais pelo ar que pela terra: verá como chegado à Região do fogo chamuscaram a Sancho, que ia de ancas com seu amo. (Anônimo, 1741 apud Abreu, 1994:75)

A presença do Quixote estaria sintetizada no artigo de Fidelino de Figueiredo ${ }^{4}$, o autor que apresenta uma sátira política sobre a queda do Marquês de Pombal intitulada Quixotada, escrita em 1777 por Nicolau Tolentino (1722-1804).

\section{Cervantes em português}

Em 1748 entra-se no âmbito das traduções de obras cervantinas. É publicada a obra Historia Nova, Famosa e Exemplar da Hespanhola Ingleza, traduzida por Reinerio Bocache e editada em Lisboa pela primeira vez pela Oficina de Pedro J. F. M. M. de Campos e em 1784 pela Oficina de Francisco Borges de Sousa. A mesma tradução é reeditada em 1805 e 1819. Também das Novelas Ejemplares, a Novela del Amante Liberal, com apenas as iniciais do tradutor (A. da C. de T. A e F), é publicada pela Oficina de Antonio Gomes em Lisboa, 1788 e reeditada em 1817. No

3 Só como exemplo, observar o comportamento das edições das traduções do século XXI. O primeiro livro do Quixote da tradução de Molina, editada em 2002, foi reeditada em 2003, 2005, 2007, 2008 e está esgotada (set. 2010). O segundo livro foi editado em 2007 e teve somente uma segunda edição, em 2008; dados disponiveis no site da Editora 34. Já a tradução de Nougué/Sánchez foi editada uma só vez em 2005, e a editora Record ainda não lançou o segundo livro.

4 Figueiredo, F. de (1920) O tema do Quixote na Literatura Portuguesa do Século XVIII. Revista de Filología Española.

TradTerm, 16, 2010, p. 193-216 
portal "Caminhos do Romance" publicada pela Oficina Joaquim Thomas de Aquino Bulhões em 1815. Abreu (1994) ressalta que o dito tradutor "nunca usa o termo tradução, antes fazendo uso dessa ambígua paráfrase de 'tirar de alguns Livros Estrangeiros, com que formar a presente história"' (Abreu, 1994:76, aspas da autora).

A mesma Oficina de Antonio Gomes publica, em 1791, sem nome de autor ou tradutor, uma novela com o título: Os acontecimentos e Sucessos do Curioso Impertinente; e da Amizade Violada pelo mais Constante e Fiel Amigo. É extraída de uma tradução da Novela del Curioso Impertinente, do primeiro livro do Quixote e teria sido usada uma edição da obra de 1788, ainda em espanhol. Na resenha cronológica das traduções feita por Rodrigues (1951) encontra-se também a Galatea, traduzida em Lisboa por Manuel Maria Barbosa du Bocage e editada pela Oficina de Simão Thadeo Ferreira em 1802.

A Typografia Rollandiana reedita a tradução em 1816, 1819 e 1820. La Señora Cornelia, das Novelas Ejemplares é traduzida e publicada em Lisboa pela Imprensa Alcobia em 1816 com o titulo Aventuras galantes de dois fidalgos Estudantes, ou a historia admirável da famosa Cornelia de Bolonha. A Oficina Francisco de Paula Campos publica a tradução da obra El celoso extremeño

5 Transcrição da apresentação do Portal Cronologia do Romance: "A cronologia abaixo pretende acompanhar a publicação de textos em prosa ficcional traduzidos para o português entre o século XVII e o XIX. A principal fonte de consulta para sua elaboração foi o inventário de A. A. Gonçalves Rodrigues. A Tradução em Portugal - tentativa de resenha cronológica das traduções impressas em lingua portuguesa, excluindo o Brasil de 1495 a 1959. Lisboa. Imprensa Nacional - Casa da Moeda, 1992. As informações sobre as obras publicadas pela Impressão Régia no Rio de Janeiro foram extraídas de CAMARGO, Ana Maria de Almeida e MORAES, Rubens Borba de. Bibliografia da Impressão Régia do Rio de Janeiro. São Paulo: EDUSP, Livraria Kosmos Editora, 1993, 2. vol. Trata-se de trabalho em elaboração, que espera contar com o auxilio de todos aqueles que localizem indicações de obras de ficção traduzidas para a lingua portuguesa no período.” Disponivel em: http://www.cami nhosdoromance.iel.unicamp.br/cronologias/traducao.htm. Acessado em 25 de outubro de 2009.

TradTerm, 16, 2010, p. 193-216 
traduzida por Jose Pedro Francisco de Paula Campos com o título: $O$ velho e a menina ou o casamento desigual, publicada Nova Imprensa da Viúva Neves \& Filhos em 1818. Essa mesma obra publica-se em Lisboa com o titulo Novellas Exemplares de Saavedra author de D. Quixote de la Mancha. Novela I- O Zeloso Estremenho, pela Imprensa J. B. Morando em 1820, também sem indicação do tradutor.

Os dados sobre as traduções feitas em Portugal nos séculos XVII e XVIII mostram que o ocorrido com o Quixote não foi um caso isolado e corresponde a uma tendência. A obra de Rodrigues apresenta 563 obras traduzidas para o português nesse período, e somente 18 delas são traduções do espanhol (algumas dessas obras são francesas), confirmando as pesquisas deste trabalho ${ }^{6}$.

\section{A tradução anônima}

Por fim, em 1794, aparece em Lisboa a primeira tradução do Quixote com o título O Engenhoso Fidalgo Dom Quixote de la

6 Outras obras traduzidas do espanhol, segundo Rodrigues: Celestina foi traduzida do francês, tradutor anônimo. Lisboa: Typografia Rollandiana, 1819. O Evangelho em triunfo, ou historia de hum Philosofo desenganado, 1802-1803. Evaristo e Theodora, ou o Castello de Clostern, traduzido por D.Francisco Grimaud de Velaunde. Lisboa: Typografia Rollandiana, 1826. A filosofia por Amor, ou Cartas de dous amantes apaixonados e virtuosos, traduzido do espanhol de uma obra de Rousseau, Nouvelle Heloise (1765), Barcelona, 1805. Lazarosinho de Tormes, traduzida por Antonio de Faria Barreyros. Lisboa: Oficina de Bernardo da Costa de Carvalho, 1721 e reeditada em 1786. A mulher feliz, dependente do mundo e da fortuna, por filosofo incógnito, traduzida pelo tradutor do "Viajante Universal", Lisboa: Rolland, 1807. Raimundo e Marianna, novela espanhola traduzida do francês por Manoel Maria Barbosa du Bocage. Lisboa, 1819. Vida e acçoens celebres e graciosas de Gusmão de Alfarache atalaia da vida humana de Matheo Aleman, Porto: Oficinas de Antonio Alvarez Ribeiro, 1793. Historia das fortunas de Sempriles e Gerenodamo de João Henríquez de Zuniga, traduzida por Antonio de Sousa da Silva. Lisboa, 1735. Vida e aventuras de Sancho Cravena,ou o homem de sete officios, 1804. Vida e sucessos do prodigioso de Sevilha. Lisboa: Typografia Rollandiana, 1819.

TradTerm, 16, 2010, p. 193-216 
Mancha. Na capa, surge a informação de que foi "traduzido em vulgar", mas não é fornecido o nome do tradutor. A edição tem seis volumes (três para cada livro); houve a eliminação dos prólogos, poemas, aprovações, dedicatórias, enfim todos os textos anteriores escritos por Cervantes antes do primeiro capítulo de cada livro. O segundo livro apresenta o mesmo título que o primeiro, sem a mudança de fidalgo para cavaleiro ${ }^{7}$.

Maria Josefa Postigo Aldeamil (1999:sp) questiona os motivos pelo qual um livro universalmente traduzido quase de imediato para outras línguas teria sido traduzido para o português tão tardiamente. Observa, assim como Abreu, que a inexistência da tradução para o português durante quase 200 anos não teria impedido que a obra fosse lida; e relembra que Portugal realizou várias reedições da obra em espanhol. A pesquisadora também acredita que uma das razões para a demora de uma versão portuguesa seria a proximidade das duas línguas, muito maior que hoje em dia, o que dispensaria a tradução. Nota-se que, segundo Rodrigues, o Quixote era lido pelo homem de letras em castelhano, "lingua que não precisava traduzir", o que é um dado significante para a discussão proposta neste artigo:

A extraordinária influencia que a novela castelhana do tipo cervantino exerceu em toda a Europa culta não despertou entre nos estímulos criadores. O português amigo das letras não deixaria de saborear o novo fruto; fazia-o, porem em castelhano, língua que não precisava de traduzir. (Rodrigues, 1951:3)

Francisco da Gama Caiero (1980) disponibiliza o texto publicado na Gazeta de Lisboa, de 27 de dezembro de 1794, e relata o lançamento dessa tradução:

Saio à luz o Engenhoso Fidalgo D. Quixote de la Mancha, por Miguel de Cervantes Saavedra, traduzido em português, em 6 vols. (...) Esta obra, vertida em todas as lín-

7 O título da obra no primeiro livro é El ingenioso Hidalgo don Quijote de la Mancha (1605); no segundo livro o fidalgo é intitulado cavaleiro: El ingenioso Caballero don Quijote de la Mancha (1615) (grifo meu).

TradTerm, 16, 2010, p. 193-216 
guas das nações cultas da Europa, de justiça aparece agora na nossa, para recreio e instrução dos Portugueses: ela é a primeira entre todos os Romances Cômicos, já pelo gosto, simplicidade e graça, já pela pureza e natural do estilo, já pela verdade dos retratos, já pela arte de narrar ${ }^{8}$ e misturar as aventuras sem nada estragar, e já, sobretudo, pelo talento de instruir divertindo; achando-se a cada pagina cômicos quadros, judiciosas reflexões, e tanta arte que todos os Sábios lhe tributam o merecimento da originalidade. (Caiero, 1980:28-29, grifos do autor)

Postigo Aldeamil sugere um nome bastante plausível para esse tradutor, até hoje anônimo:

É, em finais do século XVIII, que se começa a sentir a necessidade de ler a obra traduzida e se publicam seis pequenos volumes de tradutor anónimo que podia muito bem ter sido realizada por Francisco Rolland, o autor de Adagios, proverbios, rifãos e anexins da Lingua Portugueza, volume também publicado pela Typografia Rollandiana em 1780. (Aldeamil, 1999:04, grifos da autora)

O mesmo portal Cronologia do Romance indica uma edição da obra em português em 1830, publicada em Paris pela Pillet Aîné, em oito volumes, com o titulo $O$ engenhoso fidalgo Dom Quixote de la Mancha. Também não há indicação de tradutor. Victor Ramos (1972), em sua obra A Edição de Lingua Portuguesa em França (1800-1850), recolhe mais de 550 obras escritas em português e editadas nesse país e comenta as fases das edições em português na França:

(...) a edição de língua portuguesa na França atravessa as fases seguintes: antes da revolução de 1820 [Revolução do Porto] e apesar das invasões francesas, o movimento

8 A nota 20: Cf. Manuel Lopes de Almeida - em Noticias de Portugal e Brasil, II (1751-1800), Coimbra, 1964, pp. 285-286; Jorge Peixoto "Bibliografia das edições e traduções do D. Quixote publicadas em Portugal". In: Boletim Internacional de Bibliografia Luso-Brasileira, Fundação C. Gulbenkian, II, n 4 (Lisboa 1961), pp. 604-606.

TradTerm, 16, 2010, p. 193-216 
editorial lá fora é escasso; mas logo o vintismo vem activar os prelos franceses que imprimem na nossa língua. (Ramos, 1972:95)

Sobre esse tema, o estudioso português Guilherme G. Oliveira Santos afirma que “(...) a edição de 1830 é muito rara e pouco acessivel, e os cervantistas portugueses são, infelizmente, quase tão raros como a edição de 1830" (Santos, 1981:37). Ele descreve a edição francesa, a primeira tradução em português ilustrada, "adornada com 25 Estampas Finas" (idem: 35), e confirma ser uma "reprodução ipsis litteris da edição da Typografia Rollandiana" (idem: 38, grifos do autor).

Em 1853 a Typografia Universal publica a mesma tradução anônima de 1794 e 1830, mas com as alterações ortográficas da época, um outro título, História de D. Quixote de la Mancha, e ilustrada com gravuras assinadas pelo autor apenas como Marti. Em volume único, o segundo livro é chamado de "Parte Segunda" (Cervantes, 1830:285). Cañede (2007:59 e 2003:190) cita, em nota, outra edição da mesma tradução anônima, editada em Oporto, Portugal em $1858^{9}$.

\section{A tradução assinada}

Em 1876, surge em Lisboa, após 271 anos da primeira edição do Quixote em 1605, a primeira tradução assinada em português. É a celebrada e ainda hoje a mais editada ${ }^{10}$ tradução dos Viscondes de Castilho, de Azevedo e de Pinheiro Chagas. Considerada como a primeira edição monumental da obra em Portugal, reproduz nada menos que as famosas ilustrações de Gustave Doré. Essa tradução promovida pela Companhia Litteraria do Porto começou a ser feita pelo escritor e tradutor

9 Infelizmente em nenhum dos dois artigos a professora da Universidade de Extremadura fornece mais dados sobre essa edição de Oporto em 1858, e não foi encontrada outra menção sobre o assunto na bibliografia.

10 Dado confirmado em Portugal por Abreu (1994:255). No Brasil, 67\% das 72 edições/reimpressões são da tradução Viscondes/Chagas, cf. catálogo completo e tabelas em Cobelo (2009:118-120).

TradTerm, 16, 2010, p. 193-216 
António Feliciano de Castilho (1800-1875) ${ }^{11}$. Ele perdeu a visão aos seis anos, sequela de um surto de sarampo em sua cidade natal, Lisboa, e morreu aos 75 anos, um ano antes do lançamento da obra, em 1876. Abreu informa que o tradutor chegou ao capítulo $\mathrm{XXV}^{12}$ do primeiro livro.

Após a morte do Visconde de Castilho surge em cena o Visconde de Azevedo. Ao assumir a tradução ele tinha 66 anos de idade e também morreria um ano depois, no lançamento do primeiro livro do Quixote. Pelo tempo que dedicou ao trabalho é muito improvável que tenha traduzido mais que o primeiro livro. Abreu inclui um terceiro responsável dessa tradução do Quixote: "Pinheiro Chagas que colaborará também na tradução da Segunda Parte" (Abreu, 1994:77, grifos da autora).

Pinheiro Chagas também escreverá o prefácio da obra, que seria "o mais importante texto crítico que acerca de Cervantes e do Dom Quixote se produziu em Portugal durante o século XIX" (Abreu, 1994:83). Em outro artigo, Abreu (s.d) menciona o comentário do diretor da Biblioteca Nacional, Xavier da Cunha $(1908)^{13}$, no catálogo de A Exposição Cervantina, feito para as comemorações do tricentenário, confirmando o lisboeta Manuel Pinheiro Chagas (1842-1895) como tradutor de parte do segundo livro. O jovem autor de 34 anos teria mostrado um conhecimento da crítica cervantina da época, assim como das diversas interpretações e leituras que a recepção da obra havia causado ao longo do tempo e em várias culturas ocidentais. ${ }^{14}$ Sobre a tradução do Quixote é interessante observar a opinião de Jorge Peixoto ${ }^{15}$, citada por Abreu (1994):

11 Ver mais em http://www.apec.org.pt/castilho.htm. Acessado em 8 de julho de 2009.

12 Ou XXXV, segundo matéria no artigo em O Commercio do Porto (Abreu, 1994:254).

13 CUNHA, X. da (1908) A exposição cervantina da Bibliotheca Nacional de Lisboa. Lisboa: Imp. Nacional (Capítulo das traduções portuguesas).

14 Parte desse prefácio pode ser apreciada em Abreu (2006:305-306) e no subcapítulo O Prefácio de Pinheiro Chagas (1876) em Abreu (1994:82-92).

15 PEIXOTO, J. (1961) Bibliografia das Edições e Traduções do D. Quixote Publicadas em Portugal. Boletim Internacional de Bibliografia LusoBrasileira.Lisboa: Fundação Calouste Gulbenkian, vol. 2, p. 598.

TradTerm, 16, 2010, p. 193-216 
(...) nos meados do século XIX, as traduções dos viscondes de Castilho e de Azevedo, Pinheiro Chagas [1876-78] e de Benalcanfôr [1877] marcam um novo rumo neste capítulo. São tradutores escrupulosos e de prosa escorreita. Levados talvez pela inferioridade em que viam as nossas letras no capítulo das traduções do Quixote ou ainda tentados pelo belo exercício que tal poderia constituir, realizaram trabalho de largo merecimento. (...) "as traduções subseqüentes vão todas entroncar" na de Castiho-Azevedo-P.Chagas". (Abreu, 1994:82-83)

Adverte-se que Jorge Peixoto denomina a tradução como Castilho-Azevedo-P.Chagas. Os estudos feitos indicam que apesar de não figurar como tradutor nos créditos da edição mais publicada em português, ele deve ter traduzido grande parte da obra, possivelmente todo o segundo livro.

Em 1875, Visconde de Azevedo retoma o labor deixado pelo finado Visconde de Castilho, com apenas os primeiros 25 capítulos prontos, e falece um ano depois. Pelo tempo que dedicou ao trabalho é muito improvável que tenha traduzido para além do primeiro livro, pois a obra tem 52 capítulos na primeira parte e 74 na segunda.

Segundo Abreu, no prefácio Pinheiro Chagas faz um paralelo entre Dom Quixote e D. Sebastião, pelo "estilo cavalheiresco que ambos encarnavam" (Abreu, 1994:87) e oferece uma biografia de Cervantes. É interessante a busca, e por caminhos tortuosos, de eventos que indicassem uma relação entre Cervantes e Portugal. Menciona-se, por exemplo, uma pretensa filha do autor espanhol com uma portuguesa relacionada ao fato de Amadis de Gaula ter a autoria atribuída a um português; assim como a possibilidade de Gil Vicente, por meio de um episódio de Dom Duardos e com Juiz de Beira, ter influenciado a criação da narrativa do Quixote.

Pinheiro Chagas teria lido o Quixote apócrifo de Avellaneda em tradução francesa por não ter "encontrado nas bibliotecas lisbonenses o original hespanhol” (Abreu, 1994:89). Em relação a essa questão, Maria Fernanda Abreu (1994) relata que experiências desse tipo eram frequentes no século XIX; não se encontravam livros portugueses em Madri, nem livros espanhóis 
em Lisboa. Um articulista do jornal A Península teria reclamado da falta de livros em espanhol nas livrarias, afirmando só encontrar obras espanholas em traduções francesas oitocentistas. Esse dado é relevante por mostrar a diferença em relação aos séculos anteriores nos quais se produzia literatura em espanhol, como veremos a seguir.

\section{Um Portugal castelhano}

O bilinguismo luso-espanhol perdurou em Portugal, segundo Teyssier (1982:37-38), entre meados do século XV e final do século XVII. O espanhol era uma segunda língua para portugueses cultos. Os tradicionais casamentos reais entre as duas coroas e os 60 anos de dominação espanhola, entre 1580 e 1640, teriam aumentado mais ainda essa impregnação linguística. Ao considerar Lisboa como um vice-reinado da Espanha, a informação de que o Quixote foi editado nessa cidade, em espanhol, no mesmo ano de sua primeira publicação em Madri, não mais surpreende. Depois de 1640, com a Restauração e coroação de D. João IV, nem a reação antiespanhola foi capaz de suprimir o uso do espanhol pelos portugueses, algo que perdurou até o final do século XVII, ao perder o título de "lingua de cultura" para o francês.

Bueno (1967) afirma que o espanholismo era mais acentuado em Lisboa; havia inclusive uma estrada real de Lisboa a Madri. A "Corte na Aldeia", como era chamada a corte dos Duques de Bragança mantida durante o domínio da coroa espanhola em Vila Viçosa, apresentaria gosto pela leitura, em especial sobre relatos fabulosos de cavalaria, "que induziam ao devaneio da fantasia, ao desajustamento de que o maior representante havia de ser D. Quixote" (Bueno, 1967:122). O autor ressalta o uso do idioma espanhol por muitos escritores, a ponto de ser publicado em Madri, em 1890, um Catalogo Razonado, Biográfico y Bibliográfico de los Portugueses que escribieron en castellano. Os escritores portugueses alegariam que, por ser uma língua mais conhecida, favorecia a difusão das ideias.

Teyssier (1982:37) pesquisa autores portugueses que escreveram em espanhol, tais como Gil Vicente (1465-1580), Sá de 
Miranda (1481-1558), Luís de Camões (1524-1580), Francisco Manuel de Melo (1608-1666) e Jorge de Montemor (1520-1561), autor de Diana e que chegou a hispanizar seu nome para Montemayor, abandonando completamente sua lingua materna.

Existiria, pois, um "castelhano de Portugal", onde o lusismo se insinuava de várias maneiras; era um espanhol bem peculiar, pronunciado com sotaque local, com uma morfologia e sintaxe que muitas vezes se afastava da norma do país vizinho. Por exemplo, na obra de Gil Vicente, Floresta d'Enganos, o infinitivo flexionado do português é introduzido no espanhol: "Penitencia será harta/ pensares em mi tormento" (Teyssier, 1982:71). Os lusismos também apareciam no vocabulário - para exprimir saudade Gil Vicente usa uma nova palavra: saludad.

Maria Jesús Fernández García (2004:83-100) escreve um artigo sobre Gil Vicente em que discute as circunstâncias históricas e politicas do século XVI e parte do XVII, período de grandes intercâmbios culturais entre Espanha e Portugal. As preponderâncias politicas e culturais teriam feito os portugueses profundamente bilingues em seus estratos mais altos e em menor medida em ambientes populares. As manifestações desse bilinguismo apareceriam em vários gêneros literários, e confirma as informações anteriores sobre o teatro Gil Vicente e a poesia castelhana de Sá de Miranda. A autora estuda em especial personagens que falam espanhol no teatro, além de alguns aspectos da alternância do par espanhol/português. Comenta um outro estudo de Teyssier ${ }^{16}$, o qual discute as razões do bilinguismo de Gil Vicente; o pastor das obras religiosas falaria em castelhano como o modelo retirado do teatro de Juan Del Encina (14681529) e Lucas Fernández (1474-1542). Dentro desse modelo, o uso do espanhol se fixou como linguagem para esse tipo de pastor rústico, adorador do recém-nascido. Gil Vicente misturava pastores falando em espanhol e português.

O estudo do bilinguismo nos autores da segunda metade do século XVI mostraria que o fato ocorre por razões de tradição ou na busca de novos efeitos teatrais. Na comédia da Pastora Afea, os pastores refinados falam português ou espanhol, os

16 TEYSSIER, P. (1959) La langue de Gil Vicente. Paris: C. Klincksieck. 
rústicos, só português. A tradição é continuada pela Escola Vicentina até finais do século XVI. Nessas obras o pastor está ligado à língua castelhana.

O espanhol como língua escolhida pelo pastor renascentista responde ao fenômeno de influência literária dentro da corrente pastoril que culmina com a obra Diana, escrita pelo português Montemayor em espanhol, como foi visto acima. Em outro artigo, García (2006:566) afirma a existência de peças teatrais bilíngues ainda no século XVII, sintoma de que o público português entendia os longos versos em espanhol. Algumas personagens falavam tanto em espanhol como em português, assim como uma mistura dos dois idiomas.

Sérgio Molina, tradutor do Quixote, publicado pela Editora 34 em 2002/2007, comenta com seus entrevistadores do Cadernos de Literatura em Tradução (CTL) o bilinguismo em Portugal e suas decorrências dentro da história da tradução do Quixote em português:

Não existe uma tradução do Quixote ao português contemporâneo a Cervantes. No século XVII, no auge do bilingüismo literário, não se achava necessário traduzir do castelhano, pois os letrados portugueses - e brasileiros - eram majoritariamente bilíngües, liam sem maiores problemas o original. (...) Portanto, diferentemente do que aconteceu na Inglaterra, na França e na Alemanha, a história da tradução do Quixote em Portugal começa muito tarde, no final do século XVIII, justamente quando se dá um forte movimento para afastar o idioma da esfera do castelhano, que é quando nasce o português europeu moderno. (Villa et al. 2003:170-171)

Molina justifica a opção da edição bilingue, especialmente no caso de uma obra em espanhol editada num país lusófono:

faz sentido oferecer o texto do Quixote em espanhol para aqueles leitores que têm algumas noções do idioma ou até que o lêem fluentemente, que são cada vez mais numerosos. (...) uma edição bilíngue do espanhol é bem diferente [de uma edição bilingue de grego e português]. Todo leitor 
[lusófono], por menos que conheça o idioma, vai arriscar uma comparação. (Villa et al, 2003:165-166)

Como o bilinguismo pareceria terminar no final do século XVII e a primeira tradução do Quixote é do final do século XVIII, ainda há um intervalo de um século para entender a inexistência por quase duzentos anos de uma tradução em língua portuguesa da principal obra de Cervantes. Uma das explicações mais plausiveis é a similaridade ainda conservada nessas línguas, provinda da própria origem de cada uma delas ${ }^{17}$.

\section{O Quixote lido pelos leitores dos séculos XVII, XVIII e XIX}

Para dar ao leitor deste artigo uma noção de como os leitores portugueses leram a obra até o século XIX, transcreve-se abaixo, acompanhado do título, o início do conhecido primeiro parágrafo do primeiro capítulo Quixote. Primeiramente, o texto com sua grafia original de 1605 (fac-símile da Biblioteca Virtual Miguel de Cervantes), e da edição de 2004, para melhor visualização das mudanças entre as grafias espanholas. Note-se, por exemplo, a grafia na edição espanhola de 1605 , como o uso do cedilha e uso do / $\mathrm{x} /$ no lugar do uso atual do / $\mathrm{j} /$. No século XVII a proximidade linguística entre o par espanhol-português fica ainda mais evidente, facilitando a leitura de um lusófono.

A leitura das traduções atuais também demonstra essa proximidade entre as duas linguas. Os tradutores atuais decla-

17 Conferir estudos de Richman (1965) e Kulikowski\&Gonzales (1999). Verificar também em Cintrão (2006:69-72) o capítulo sobre "Competência tradutória" A pesquisadora propõe dois aspectos da proximidade linguística os quais facilitariam a leitura. O primeiro é a similitude lexical (grande número de cognatos compartilhados), o segundo, a similitude entre sistemas gramaticais e sintáticos. Esses dois aspectos facilitam o entendimento de um indivíduo monolíngue mesmo antes de sua exposição a um aprendizado formal. Segundo a autora, o português funciona muito bem como uma base transferivel para o espanhol, ressaltando ser na língua escrita culta o registro no qual os idiomas português e o espanhol parecem mais próximos.

TradTerm, 16, 2010, p. 193-216 
ram uma aproximação ao texto espanhol e a preferência por manter as inversões sintáticas do estilo de Cervantes, assim como tudo que "morfológica e sintaticamente fosse igual comum ao espanhol e ao português de então" (Nougué \& Sánchez, 2005:15). Afirmam que só utilizaram palavras que surgiram no português até o século XVII. ${ }^{18}$ Essa opção tradutória leva sempre a uma aproximação ao texto de origem, como é o caso do uso de acepções pouco usadas no Brasil, como olha (Nougué/Sánchez); o uso de salpicão - que em português atual remete a outro prato; e o empréstimo do termo duelos y quebrantos nas duas traduções do século XXI, diferente das escolhas das traduções do século $\mathrm{XX}^{19}$.

18 Fragmento da Nota dos Tradutores Nougué/Sánchez: "Em que português verter o Quixote? Pô-lo em português moderno não seria propriamente traduzir, mas adaptar. Não era essa nossa proposta. Pretendiamos traduzi-lo resolvendo uma como 'equação de três incógnitas': como escreveria Cervantes o Quixote no português de sua época, mas sem perder o sabor hispânico de então e, ainda, de modo compreensivel para o leitor de hoje? (Nougué e Sánchez, Cervantes, 2005:13). Há grande semelhança com o discurso de Molina, em especial na entrevista ao CLT, que diz que manterá as construções sintáticas no segundo livro mesmo que pareçam espanholizantes, algo que soaria como os escritos do português clássico (Villa et al. 2003:173).

19 Como comparação, vejam-se outras traduções para a mesma frase: 1 - Panelada de algo que era mais vaca do que carneiro, guisado na maioria das noites, ovos fritos com torresmos* aos sábados, (...)*Nota: No original: duelos y quebrantos [e segue texto da discussão crítica sobre essa expressão, menciona Rodriguez Marin e as traduções portuguesas] (Cervantes, 1958:35, tradução Andrade/Amado, nota e grifos da edição).

$2-($...) cozido, obrigado mais vêzes a vaca do que a carneiro, com o infalivel empadão dos sobejos à ceia, uma fritada de ovos com miúdos e toicinho aos sábados, (...) (Cervantes, 1963:43, tradução de Aquilino). 3 - Cozidos, em que havia mais de vaca que de carneiro; guisados na maioria das noites, duelos-e-quebrantos* aos sábados, (...) *Nota: Fritada de ovos com torresmos, conforme demonstrou Rodriguez Marin em alentada pesquisa (Cervantes, 1991:27, tradução de Eugênio Amado, nota e grifos da edição).

4 - Um cozido com mais vaca que carneiro, salpicão no mais das noites, duelos y quebrantos aos sábados, (...) (Cervantes, 2005:55, tradução de

TradTerm, 16, 2010, p. 193-216 


\begin{tabular}{|} 
PRIMERA PARTE DEL INGENIOSO \\
hidalgo don Quixote de la Mancha. \\
Capitulo Primero. Que trata de la condicion, y exercicio del famoso hidalgo don Quixote de la Mancha. \\
N Vn lugar de la Mancha, de cuyo nombre no quiero acordarme, no ha mucho tiempo que viuía vn \\
hidalgo de los de lança en aftillero, adarga antigua, rozin flaco, y galgo corredor. Vna olla de algo \\
mas vaca que carnero, falpicon las mas noches, duelos y quebrãtos los Sabados, lantejas los \\
Viernes, algun palomino de añadidura los Domingos: conf umian las tres partes de fu hazienda \\
(CERVANTES, 1605:Fol.I, mayúsculas e itálicos da edição). \\
\hline PRIMERA PARTE DEL INGENIOSO HIDALGO \\
DON QUIJOTE DE LA MANCHA \\
CAPÍTULO PRIMERO \\
Que trata de la condición y ejercicio del famoso y valiente hidalgo don Quijote de la Mancha. \\
En un lugar de la Mancha, de cuyo nombre no quiero acordarme, no ha mucho tiempo que vivía \\
un hidalgo de los de lanza en astillero, adarga antigua, rocín flaco y galgo corredor. Una olla de \\
algo más vaca que carnero, salpicón las más noches, duelos y quebrantos los sábados, lantejas los \\
viernes, algún palomino de añadidura los domingos, consumían las tres partes de su hacienda20 \\
(CERVANTES, 2004:27, maiúsculas e itálicos da edição).
\end{tabular}

Figura 1: Quixote em espanhol

No quadro abaixo, transcreve-se o mesmo trecho na tradução anônima de 1794 e na reimpressão de 1853, a qual, podese verificar, é idêntica à de 1794 . Em seguida, a tradução assinada pelos Viscondes de Castilho, de Azevedo e Pinheiro Chagas, na sua primeira edição comercial brasileira, pela editora Cultura, em 1943.

Molina grifos da edição). A nota aparece ao final da frase e explica " $D u$ elos y quebrantos": certo prato que não rompia a abstinência de carnes, que se observava aos sábados. Até hoje não se estabeleceu com certeza sua composição, embora a maioria dos estudiosos o identifique como uma espécie de mexido de ovos com toucinho. (...) numa tradução literal, significa algo como "dores e desalentos" (Cervantes, 2005:61, tradução de Molina grifos da edição).

5 - Uma olha com algo mais de vaca que de carneiro, * salpicão** na maioria das noites, duelos y quebrantos aos sábados, (...) Nota*: (...) por que a CARNE DE VACA era mais barata que a CARNE DE CARNEIRO. OLHA: "cozido preparado com carnes, toucinho, legumes e tubérculos, principalmente grãos-de-bico e batatas, a que se acrescentava às vezes algum enchido" (Cervantes, 2005:45, tradução de Nougué/Sánchez, maiúsculas, grifos e notas da edição).

20 Extraído das Notas de RICO: Astillero: era o cabide no qual eram penduradas as armas. Adarga: escudo leve, feito de pele. Rocín: cavalo de trabalho. Salpicón: Fiambre preparado con os restos de refeição. Duelos y quebrantos: talvez ovos com toucinho ou linguiça. Añadidura: como prato especial. Hazienda: sua renda (Cervantes, 2004:27, traduzido por Cobelo). 


\begin{tabular}{|c|c|}
\hline & $\begin{array}{l}\text { O ENGENHOSO FIDALGO D.QUIXOTE DE LA MANCHA. } \\
\text { PARTE PRIMEIRA. } \\
\text { Em que se dá conta da condiçaõ, e exercicio do famoso Fidalgo D. Quixote de la Mancha. } \\
\text { Naõ ha muito que n'hum lugar da Mancha de cujo nome naõ quero lembrar-me, vivia hum Fidalgo } \\
\text { destes que tem lança em cabide, adarga antiga, seu rocim magro, e algum galgo corredor. Huma } \\
\text { panella que pouco mais vacca levava que carneiro, as mais das noites carne que lhe sobejava do } \\
\text { jantar picada com cebolla, e vinagre, óvos fritos com miólos de carneiro aos Sabbados, ás Sextas } \\
\text { feiras lentilhas, e algum pombinho de mais ao Domingos, eis-aqui em que consumia tres partes da } \\
\text { sua fazenda (CERVANTES, } 1794: 1-2 \text {, maiúsculas, negritos e itálicos da edição). }\end{array}$ \\
\hline & $\begin{array}{l}\text { D. QUIXOTE DE LA MANCHA. } \\
\text { PARTE I. } \\
\text { EM QUE SE DÁ CONTA DA CONDIÇÃO, E EXERCICIO DO FAMOSO FIDALGO D.QUIXOTE DE LA } \\
\text { MANCHA. } \\
\text { Não ha muito que n'um logar da Mancha de cujo nome não quero lembrar-me, vivia um fidalgo } \\
\text { destes que tem lança em cabide, adarga antiga, seu rocim magro, e algum galgo corredor. Uma } \\
\text { panela que pouco mais vaca levava que carneiro, as mais das noites carne que lhe sobejava do } \\
\text { jantar picada com cebolla, e vinagre, ovos fritos com miolos de carneiro aos Sabbados, ás Sextas } \\
\text { feiras lentilhas, e algum pombinho de mais aos Domingos, eis-aqui em que consumia tres partes da } \\
\text { sua fazenda (CERVANTES, 1853:3, maiúsculas e negritos da edição). }\end{array}$ \\
\hline & $\begin{array}{l}\text { LIVRO PRIMEIRO CAPÍTULO I } \\
\text { Que trata da condição e exercício do famoso fidalgo D. QUIXOTE DE LA MANCHA } \\
\text { Num lugar da Mancha, de cujo nome não quero lembrar-me, vivia, não há muito, um fidalgo dos de } \\
\text { lança em cabido, adarga antiga, rocim fraco, e galgo corredor. } \\
\text { Passadio, olha seu tanto mais de vaca do que de carneiro, as mais das ceias restos da carne picados } \\
\text { com sua cebola e vinagre, aos sábados outros sobejos ainda somenos, lentilhas às sextas-feiras, } \\
\text { algum pombito de crescença aos domingos, consumiam tres quartos do seu haver. (CERVANTES, } \\
\text { 1943, maiúsculas e negritos e da edição). }\end{array}$ \\
\hline
\end{tabular}

Figura 2: Quixote em português

Ao comparar os dois fac-símiles das traduções portuguesas, a anônima de 1794/1853 e a Viscondes/Chagas (1876/ 78 ), com o texto em espanhol, percebe-se que o sentido implícito de alguns termos era muito bem compreendido, como na frase "Una olla de algo más vaca que carnero, salpicón las más noches, duelos y quebrantos los sábados (...)" (Cervantes, 2004:27). O termo salpicón é vertido como carne que lhe sobejava do jantar picada com cebolla, e vinagre (Anônima), e restos da carne picados com sua cebola e vinagre (Viscondes/Chagas), com um sentido mais próximo que guisado (Andrade/Amado), empadão dos sobejos (Ribeiro) ou mesmo salpicão (Molina e Nougué/Sánchez), como foi visto acima. O termo duelos y quebrantos, que é traduzido como ovos fritos com miolos de carneiro (Anônima), está muito mais próximo do sentido do texto cervantino ${ }^{21}$ que da tradução do século XIX: outros sobejos ainda somenos (Viscondes/Chagas), opção que será retomada por Andrade/Amado e Aquilino Ribeiro.

21 Ver nota 21.

TradTerm, 16, 2010, p. 193-216 


\section{Digressões Tradutológicas}

Walter Benjamin (2001) acredita que as traduções surgem quando obra alcança sua fama. Não é o caso do Quixote, que apesar da primeira tradução portuguesa distar quase dois séculos da edição do original, a obra em espanhol foi editada sincronicamente nos dois países, e rapidamente obteve fama, influência e recepção em Portugal (e no mundo ocidental), como apontamos no início. O autor faz uma colocação importante para essa reflexão: "o original se modifica" (Benjamin, 2001:197); isto é, ocorreria uma maturação, o que antes era novo, depois envelhece. O corrente soaria antiquado, já que, no caso do Quixote, a fala arcaica do cavaleiro, a fabla ${ }^{22}$, poderia ficar incompreensível. Em outras palavras, o texto original é datado. O lusófono só teria sentido diante da necessidade de uma tradução para o português quando o Quixote chegou ao 189 anos de existência, afastando-se de sua língua de partida e muito mais do português. Para Benjamin, a língua do tradutor também se transforma: "mesmo a maior tradução está fadada a desaparecer dentro da evolução da sua língua e soçobrar em sua renovação" (Benjamin, 2001:97). Esse fato não se confirma no caso do Quixote, pois, como dito antes, a tradução mais editada na língua portuguesa até hoje é a primeira, assinada por Viscondes/Chagas.

Antoine Berman (2002) discute a influência do bilinguismo e da "língua de cultura" dentro de um sistema linguístico, no caso o alemão. As traduções na Alemanha do século XVIII e XIX estavam ligadas, por exemplo, a

uma situação cultural na qual a língua nacional ainda não se auto-afirmou, em que não se pode nem acolher as outras línguas em sua diferença, nem se colocar como uma lingua "culta"; situação na qual os membros da comunidade lingüística podem ficar tentados a falar outras linguas mais "educadas". (Berman, 2002:265)

22 Molina faz referência aos problemas da tradução da fabla na citada entrevista para CLT: um dialeto literário, que só existe nas novelas de cavalaria, e que Cervantes faz uma montagem deliberada, que não é a fabla 'pura' (Villa et al. 2003:169, grifos dos autores).

TradTerm, 16, 2010, p. 193-216 
E em seguida Berman discute como o bilinguismo cultural impediu a concepção de traduções:

Assim, o bilinguismo cultural bloqueará, ao mesmo tempo e durante um longo período, o desenvolvimento literário da língua materna e o das traduções. Pois esse bilingüismo não significa uma abertura para o estrangeiro, mas antes o fato de ser dominado por este último. Tão logo a língua materna se afirma como língua de cultura, a comunidade que se define por ela pode pensar em traduzir linguas estrangeiras em vez de as falar. Inversamente, a língua materna não pode se afirmar como lingua de cultura enquanto não tiver se tornado lingua de tradução, enquanto aqueles que a falam não se interessarem por quem é estrangeiro. (Berman, 2002:265-266, grifos do autor)

É bem significante este ponto de vista: o bilinguismo não significando uma abertura para o estrangeiro, mas a dominação deste último, perturbando, assim, o fluxo tradutório editorial.

Para Aubert (1993) "a diversidade é a própria justificativa, a razão de ser da tradução. Não fossem diversos os códigos, as culturas, os momentos históricos, os homens, não haveria motivo para se traduzir" (Aubert, 1993:76). No mesmo sentido Amparo Hurtado Albir (2007) afirma que

Traduz-se porque as línguas e as culturas são diferentes; portanto, a razão de ser da tradução é a diferença linguística e cultural (...). Traduz-se para alguém que não conhece a lingua, e geralmente, nem a cultura, do texto escrito. (...) O propósito comunicativo da tradução, nascido da necessidade de comunicação para superar a barreira da diferença lingüística e cultural, é crucial na reflexão sobre a tradução ${ }^{23}$ (Albir, 2007:28-29, grifos do autor).

23 "Se traduce porque las lenguas y las culturas son diferentes; la razón de ser de la traducción es, pues, la diferencia lingüística y cultural. (...) Se traduce para alguien que no conoce la lengua, y generalmente tampoco la cultura, en que está formulado el texto escrito. (...) La finalidad comunicativa de la traducción, nacida de la necesidad de comunicación

TradTerm, 16, 2010, p. 193-216 
Podemos inferir, então, que até o final do século XVIII não haveria entre Portugal e Espanha, diversidade ou barreira linguística e cultural a ponto de exigir um ato tradutório. O lançamento, em Portugal, de Quixote em sua lingua original, o espanhol, teria uma explicação histórica: além dos reinos estarem unificados numa só coroa, a existência de um bilinguismo cultural luso-espanhol muito forte durante 250 anos, persistindo até final do século XVII. A familiaridade dos portugueses com o idioma espanhol e a similaridade e a proximidade entre essas duas línguas irmãs permitiram a leitura da obra em espanhol até o momento de sua primeira tradução, em 1794. Talvez já existisse em Portugal, uma "noção ou fantasia de uma única meta-língua ibérica" (Aubert, 1995/1997:13). Assim, enquanto tal noção perdurou, não surgiu a necessidade de uma tradução em português, nem um tradutor ou editor que acreditasse ser imperativo verter o Quixote para o português e tornar as aventuras e desventuras do valente cavaleiro e seu fiel escudeiro acessíveis ao universo de todos os leitores lusófonos.

\section{Referências Bibliográficas}

ABREU, M. F. de (1994) Cervantes no Romantismo Português. Lisboa: Editorial Estampa.

(s.d) O Quixote em Portugal e na Biblioteca Nacional. Portal da Biblioteca Nacional Digital. Disponivel em: http://purl.pt/920/1/ quixote-pt-2.html. Acesso em 9 de julho de 2009.

(2006) O Quixote na voz dos escritores portugueses. In: VIEIRA, M.A. da C. (org.) Dom Quixote - A letra e os caminhos. São Paulo: EDUSP.

ALDEAMIL, M. J. P. (1999) Os provérbios de Don Quijote de la Mancha nas traduções em português. Sexto Congresso da Associação Internacional de Lusitanistas. Rio de Janeiro. (s.p) Disponivel em http:// members.fortunecity.com/prgalvao/Osproverbiosdonquixote.htm. Acesso em 7 de junho de 2005.

para subsanar la barrera de la diferencia lingüística y cultural, es crucial en la reflexión sobre la traducción".

TradTerm, 16, 2010, p. 193-216 
AUBERT, F. H. (1993) As (In)Fidelidades da Tradução. Campinas: Editora da Unicamp.

(1995-1997) Globalização, o Idioma Castelhano e a Tradução no Brasil. Revista da APEESP. São Paulo, pp. 11-15.

BENJAMIN, W. (2001) A tarefa-renúncia do Tradutor. Clássicos da Teoria da Tradução. Florianópolis: Universidade Federal de Santa Catarina, pp. 25-49.

BERMAN, A. (2002) A prova do estrangeiro. Bauru, SP: EDUSC. Trad. Maria Emília Pereira Chanut.

BIBLIOTECA Virtual Miguel de Cervantes. Disponivel em: http:/ /www. cervantesvirtual.com/servlet/SirveObras/cerv/ 123710675590182 88532624/ima0024.htm. Acesso em 3 de setembro de 2010.

BUENO, F. da S. (1954) Estudos de Filologia Portuguesa. São Paulo: Saraiva.

(1967) A Formação Histórica da Lingua Portuguesa. São Paulo: Saraiva.

CAIERO, F. da G. (1980) Livros e Livreiros Franceses em Lisboa, nos fins de setecentos e no primeiro quartel do século XIX. Coimbra: Coimbra Editora.

CAÑETE, C. M. C. F. de (2007) Primera aproximación al Vizconde de Benalcanfor y a su traducción de Don Quixote de la Mancha. In: DASILVA, X.M. (ed.). Perfiles de la traducción hispano-portuguesa, II. Vigo: Editorial Academia del Hispanismo, pp. 59-68. (2003) In: Actas del I Congreso de la Asociación de Lusitanistas del Estado Español. Palma de Mayorca. Universitat de les Illes Balears, pp. 150-155. Disponivel em http://www.emblematica.com/alee/actas.pdf. Acesso em 7 de julho de 2010.

CELADA, M. T. (2002) O espanhol para o brasileiro: uma lingua singularmente estrangeira. Tese de Doutorado em Letras. Campinas: UNICAMP/IEL.

CERVANTES, M. de (2005) O engenhoso fidalgo D. Quixote da Mancha. Rio de Janeiro: Record, vol. 1. Trad. Carlos Nougué e José Luís Sánchez.

(2008) O engenhoso cavaleiro D. Quixote de La Mancha. São Paulo:

Editora 34. Trad. Sérgio Molina. Edição bilingue. (2004) Don Quijote de la Mancha. Real Academia Española. São Paulo: Prol Gráfica, Edición del IV Centenario. (1991) O Engenhoso Fidalgo Dom Quixote De La Mancha. Trad. Eugenio Amado. Belo Horizonte: Villa Rica, vol. 1.

TradTerm, 16, 2010, p. 193-216 
(1963) O Engenhoso Fidalgo Dom Quixote de la Mancha. São Paulo:

Difusão Européia do Livro, vol. 1. Trad. Aquilino Ribeiro.

(1958) Dom Quixote de la Mancha. Rio de Janeiro: José Olympio, vol. 1. Trad. Almir de Andrade e Milton Amado.

(1942) Dom Quixote de la Mancha. São Paulo, Edições Cultura, vol. 1. Trad. Visconde de Castilho e de Azevedo.

(1853) Historia de D. Quixote de la Mancha. Lisboa: Typografia Universal. Tradução anônima. Disponivel em http://books.google. com.br/books?id=rxkPAAAAYAAJ\&dq=Historia + de + D. + quixote + de +1 $\mathrm{a}+$ mancha $+1853 \&$ source $=$ gbs_navlinks_s. Acesso em 17 de novembro de 2008 .

(1794) O Engenhoso Fidalgo Dom Quixote de la Mancha. Lisboa: Typografia Rollandiana. Tradução anônima. Disponivel em: http:// books.google.com.br / books?id=troGAAAAQAAJ\&pg=PP1 $1 \&$ dq=dom +quixote+1794\&ei=AGvrSvujB5KWzgSWuaG3Dw\#v=onepage $\& q=\& f=$ false . Acesso em 7 de novembro de 2008.

(1605) Don Qvixote de la Mancha. Fac-simile disponivel em http:/ /www.cervantesvirtual.com/servlet/SirveObras/cerv/ 1237106755 9018288532624/ima0024.htm. Acesso em 3 de setembro de 2010.

CINTRÃO, H.P. (2006) Colocar Lupas, Transcriar Mapas - Iniciando o desenvolvimento da competência tradutória em nivel básico de espanhol como LE. Tese de Doutorado. São Paulo: FFLCH-USP.

COBELO, S. (2009) Historiografia das traduções do Quixote publicadas no Brasil - Provérbios do Sancho Pança. Dissertação de Mestrado. São Paulo: FFLCH/USP.

EDITORA 34. Disponivel em: http://www.editora34.com.br/quem somos.htm. Acesso em: 4 de setembro de 2010.

EDITORA RECORD. Disponivel em http://www.record.com.br/livro_ sinopse.asp?id_livro=19278. Acesso em 4 de setembro de 2010.

GARCÍA, M. J. F. (2004) Personajes que hablan castellano en el teatro portugués del siglo XVI: (II), El Pastor. Cáceres: Anuario de Estudios Filológicos, vol. 27, pp. 83-100.

(2006) Portunhol y Literatura. Revista de Estudios Extremeños. Badajoz, vol. 62, pp. 555-577. Disponivel em www.dip-badajoz.es/ .../reex/rcex.../estudios_02_rcex_2_2006.pdf. Acesso em 11 de novembro de 2010.

KULIKOWSKI, M. Z. M.; GONZÁLES, N. T. M. (1999) Español para brasileños. Sobre por dónde determinar la justa medida de una

TradTerm, 16, 2010, p. 193-216 
cercanía. Anuario brasileño de estudios hispánicos. Brasília: $\mathrm{n}^{\circ} 9$, pp. 11-19. Disponivel em http://www.educacion.es/exterior/br/es/ publicaciones/anuario/abeh99. pdf\#page=11. Acesso em 11 de novembro 2010.

MONTES, José Ares. (1953) Don Quijote en el teatro portugués del siglo XVIII. Anales Cervantinos.

PORTAL Cronologia do Romance. Disponível em http://www.cami nhosdoromance.iel.unicamp.br/cronologias/traducao.htm. Acesso em 25 de outubro de 2009.

RAMOS, V. (1972) A edição de Língua Portuguesa em França (18001850). Repertorio Geral dos Titulos Publicados e Ensaio Critico. Serie Memórias e Documentos para a Historia Luso-Francesa - X Paris, Fundação Calouste Gulbenkian, Centro Cultural Português.

RICHMAN, S.H. (1965) A Comparative Study of Spanish and Portuguese Michigan: University of Microfilms, Inc.

RODRIGUES, A. G. (1951) A Novelística estrangeira em versão portuguesa no periodo pré-romântico. Coimbra: Biblioteca da Universidade.

SANTOS, G. G. de O. (1981) Ao redor de duas Edições do "Dom Quixote de la Mancha". Lisboa: Livraria Portugal, 121p.

TEYSSIER, P. (1984) História da Língua Portuguesa. Lisboa: Editora Livraria Sá da Costa.

VILLA, D; BENEDETTI, I.; HIRSCH, I. (2003) Entrevista com Sérgio Molina. Cadernos de Literatura em Tradução (CLT). São Paulo: Humanitas/FFLCH-USP, n. 5, pp. 157-171.

TradTerm, 16, 2010, p. 193-216 